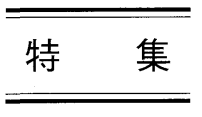

\title{
The Training of Cytopathologists in the United States
}

\author{
Associate Professor of Pathology, Harvard Medical School, Boston, Massachusetts, USA \\ Director of Cytopathology, Brigham and Women's Hospital \\ Edmund S. Cibas, M.D.
}

In the United States, abnormal gynecologic samples (including cases that show "reactive/reparative" changes) and all non-gynecologic cytology cases must be reviewed by a doctor of medicine. Licenses to practice medicine are granted by the 50 States, not by the federal government, and are based on successful completion of a school of medicine. In addition, he or she must also have passed the board examination in Anatomic Pathology given by the American Board of Pathology (ABP) (www.abpath.org). (Those who practice osteopathic medicine also qualify, given a similar set of licenses and board examinations.)

To qualify for taking the board examination in Anatomic Pathology, a candidate must complete a residency training program in Anatomic Pathology (three years) or combined Anatomic and Clinical Pathology (four years). Anatomic Pathology encompasses Surgical Pathology, Cytopathology, and Autopsy Pathology, whereas Clinical Pathology is comprised of Hematology, Chemistry, Microbiology, and Blood Banking. All residency training programs, including pathology, are accredited by The American College of Graduate Medical Education (ACGME) (www.acgme.org). In the current academic year (2002-2003) there are 153 accredited pathology residencies in the United States, which train a total of 2,153 residents. The ACGME has a Residency Review Committee (RRC) for pathology

論文別刷請求先 ₹ 320-8580 栃木県宇都宮市中戸祭 1 の 10 の 37 国立病院機構栃木病院 長谷川壽彦

平成 16 年 2 月 12 日受付

平成 16 年 7 月 1 日受理 training programs, which sets the standard for pathology residency programs in the United States. The RRC sends inspectors to perform a site visit of every program at least every 5 years (sometimes more often, if there were deficiencies during the prior review) to ensure that standards are being met.

On average, a pathology resident spends 3 months training in cytopathology (Davey, 1996), but most program directors believe training in cytopathology should be longer (4.5 months). Each residency program develops its own structure and curriculum for teaching cytopathology. As a result, there is significant variation in the way cytopathology is taught among the many residency training programs. But they all have to meet the standards set by the RRC. The RRC expects that certain essential skills in cytopathology be taught. These are :

- Microscopic diagnostic skills, which are learned through

- involvement in daily case evaluation

- attendance at teaching conferences

- review of teaching cases

- reading books and journals

- Ability to provide consultation on the role of cytopathology in clinical medicine

- Technical skills (performing fine-needle aspirations)

- Interpersonal (communication) skills (with patients, other doctors)

- Teaching skills

The RRC provides some guidelines for program directors. For example, it requires that every pathol- 


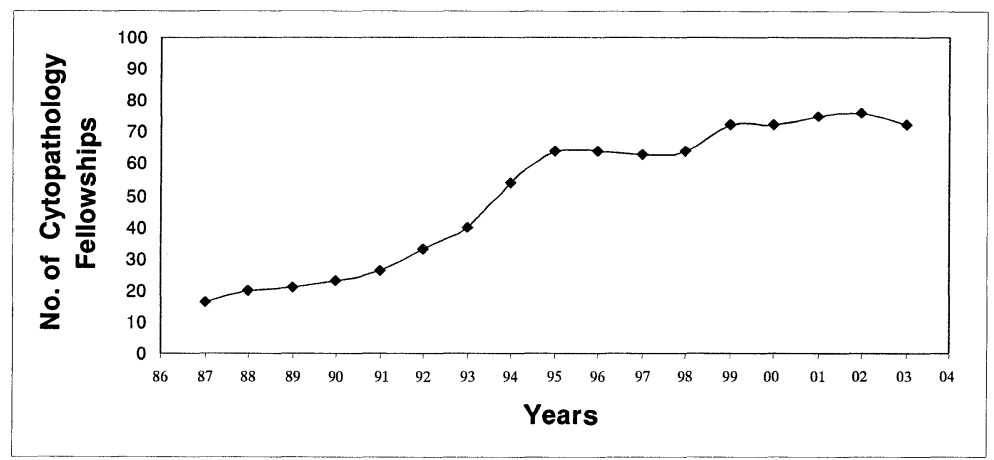

Fig. 1 Number of Cytopathology Fellowship Programs in the United States 19862003

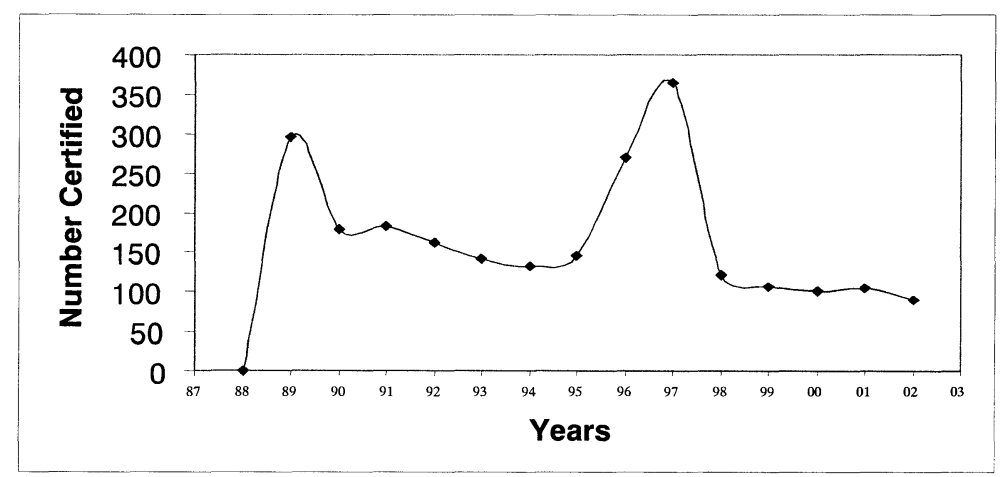

Total Certified 1989-2002 $=2,392$

Fig. 2 Number of Persons Certified by the American Board of Pathology for Added Qualification in Cytopathology

ogy resident examine at least 1,500 cytologic specimens during his or her residency. The RRC also requires that residents learn to perform fine-needle aspirations. The program director is ultimately responsible for evaluating each resident to make sure that these educational goals are being met.

As a resident nears completion of his or her pathology training, they apply to take the examination in Anatomic (or combined Anatomic and Clinical) Pathology. As mentioned above, certification in Anatomic Pathology is granted by the ABP. The ABP has been administering certification examinations since 1936. The ABP converted to computerized examinations in 1994. Computerized examinations have proven to be much more efficient than the traditional examinations using paper and pencil. Results are available in a matter of days rather than weeks. The test is a written examination that includes the interpretation of electronic images as well as microscopic glass slides. Questions related to cytopathology form a large part of this examination.

Because of the increasing role of cytopathology in the practice of medicine, the last twenty years have seen a significant growth in the number of cytopathology fellowship programs (Fig. 1), which are usually one-year programs for residents who seek advanced training. The RRC began the accreditation of cytopathology fellowship programs in 1992. Over the past 10 years, the number of accredited programs has increased from 32 to 82 . Most programs have only one cytopathology fellow, but some have 2 or more. In the current academic year (2002-2003), there are $99 \mathrm{cy}$ topathology fellows in the United States.

The ABP began offering certification for "added 
qualification" in Cytopathology in 1989. Like the examination in Anatomic Pathology, the added qualification in Cytopathology is a written examination that includes interpretation of electronic images as well as microscopic glass slides. Between 1989 and 2002 a total of 2,392 individuals have been granted added qualification in Cytopathology (Fig. 2). Before 1998, it was possible to take this examination without doing a cytopathology fellowship, but since 1998 a cytopathology fellowship has been required for taking the examination. The "added qualification" in Cytopa- thology is an acknowledgment of special achievement, but is not required to practice cytopathology in the USA. At the present time, most individuals who practice cytopathology in the USA do not have added qualification in Cytopathology.

\section{Reference}

Davey, D.D., Talkington, S., Kannan, V., Masood, S., Davila, R., Cohen, M. Cytopathology and the pathology resident. Arch Pathol Lab Med $1996 ; 120: 101-104$. 